\title{
Dört Rotorlu İnsansız Hava Aracının Kayan Kipli Denetleyici ve Geri Adımlamalı Denetleyici ile Yönelim ve Yükseklik Denetimi
}

\author{
Ebubekir BOZKURT ${ }^{1 *}$, Beşir DANDIL ${ }^{2}$, Fikret ATA ${ }^{3}$ \\ ${ }^{1}$ Makine Programı, Teknik Bilimler MYO, Bingöl Üniversitesi, Bingöl, Türkiye \\ ${ }^{2}$ Mekatronik Mühendisliği, Teknoloji Fakültesi, Fırat Üniversitesi, Elazığ, Türkiye \\ ${ }^{3}$ Elektrik-Elektronik Mühendisliği, Mühendislik Mimarlık Fakültesi, Bingöl Üniversitesi, Bingöl, Türkiye \\ 1ebozkurt@bingol.edu.tr, ${ }^{2}$ bdandil@ firat.edu.tr, ${ }^{3}$ fata@bingol.edu.tr
}

(Geliş/Received: 20/11/2019;

Kabul/Accepted: 08/02/2020)

\begin{abstract}
Öz: Bu çalışmada dört rotorlu insansız hava aracının(quadrotor) dinamik denklemleri yardımı ile Matlab/Simulink ortamında benzetim modeli oluşturularak, hava aracının yönelim ve yükseklik denetimleri gerçekleștirilmiştir. Quadrotorlar yapısal olarak dört rotordan oluşan doğrusal olmayan dinamik yapısı ve her bir rotoru harekete geçiren motorların hız denetiminin gerekliliğinden dolayı denetimi zor sistemlerdir. Doğrusal olmayan bir matematiksel modele sahip olan quadrotorun yükseklik ve yönelim değişkenlerinin denetimi için, doğrusal olmayan yapıya sahip Kayan Kipli Denetleyici ve Geri Adımlamalı Denetleyici tasarlanmıştır. Tasarlanan Kayan Kipli Denetleyici ve Geri Adımlamalı Denetleyici benzetim modeli üzerinde test edilmiştir. Benzetim çalıșmalarından elde edilen denetim sonuçları quadrotorun doğrusal olmayan sistem yapısına sahip olmasına rağmen her iki denetim yöntemi için denetim başarımı elde edildiğini göstermiştir. Ancak Kayan Kipli Denetleyici ile yapılan denetimden elde edilen denetim başarımı yerleşme zamanının, Geri Adımlamalı Denetleyici ile yapılan denetimden elde edilen denetim başarımı yerleşme zamanına göre daha kısa sürede elde edildiği görülmüştür.
\end{abstract}

Anahtar Kelimeler: Dört rotorlu insansız hava aracı, Quadrotor, Kayan kipli denetleyici, Geri adımlamalı denetleyici.

\section{Orientation and Altitude Control of A Four-Rotor Unmanned Aerial Vehicle with Sliding Mode Control and Back-Stepping Control}

\begin{abstract}
In this study, a simulation model was created in the Matlab-Simulink environment with the help of dynamic equations of the four-rotor unmanned aerial vehicle, the orientation and altitude controls of the four-rotor unmanned aerial vehicle were performed. The quadrotor is a system that is difficult to control due to the non-linear dynamic structure consisting of four-rotor and the necessity of speed control of the motors driving each rotor. For the control of the altitude and orientation variables of the quadrotor which has a non-linear mathematical model, a non-linear Sliding Mode Controller and non-linear Back-stepping Controller are designed. The designed Sliding Mode Controller and Back-stepping Controller were tested on the simulation model. The control results obtained from the simulation studies showed that although the quadrotor has a nonlinear system structure, control performance was achieved for both control methods. However, it has been observed that the time to settle the control performance obtained from the control made with Sliding Mode Controller is less than the time to settle the control performance obtained from the control conducted with Back-stepping Controller.
\end{abstract}

Key words: A four-rotor unmanned aerial vehicle, Quadcopter, Sliding mode controller, Back-stepping controller.

\section{Giris}

Dört rotorlu insansız hava araçları; tehlikeli, hassas pilotaj gerektiren güvenlik, gözetim, hedef tespiti ve takibi gibi insanların can güvenliğini tehlikeye atabilecek uygulamalarda, trafik denetimi, doğal afet sonrası hasar tespiti, suç mahalli araştırması, sınır güvenliği sağlama, arama kurtarma, zirai işler gibi geniş uygulama alanlarına sahiptirler. Bu hava araçları, dinamik yapısı gereği dört adet rotordan ve pervanelerin dönmesi sonucu oluşan itki kuvveti ile uçabilen, yörünge takibi yapabilen araçlarıdır. Sistemin dinamik yapısı sisteme yüksek itki kuvveti sağlamakta ve yapılması zor olan hareketlerin yapılabilmesine olanak sağlamaktadır. Ancak aracın dört rotordan oluşan doğrusal olmayan dinamik yapısı ve her bir rotoru harekete geçiren motorların hız denetiminin gerekliliği sistem denetimini zorlaştırmaktadır. Bu denetimin zorluğu ve geliştirilmeye ihtiyaç duyulması nedeniyle literatürde pek çok araştırma yapılmış ve günümüzde bu konu üzerinde akademik çalışmalar devam etmektedir.

\footnotetext{
* Sorumlu yazar: ebozkurt@bingol.edu.tr. Yazarların ORCID Numarası: ${ }^{1} 0000-0001-9335-7188,{ }^{20000-0002-3625-5027, ~}{ }^{3} 0000-0003-1100-$ 6179.
} 
Bu çalışmaların önemli bir bölümü dört rotorlu hava araçlarının güvenli uçuşu ve yüksek performanslı izleme yeteneği üzerine yapılmışıtır [1-5].

Quadrotorlar üzerine literatürde yapılmış çalışmaların bazılarından bahsedilecek olunursa; Remeo F. ve arkadaşları; quadrotorun ölçülebilir açı ve pozisyonları vasıtasıyla dış bozucu ve belirsizliklerin etkisi altında takip problemiyle başa çıkabilme durumunu incelemişlerdir. Quadrotor denetimi için dört farklı sürekli kayan kipli denetim algoritması ve sağlamlaştırılmış PID denetleyici ile ilgili karşılaştırmalı analizini sunmuşlardır[6]. Bing $\mathrm{X}$. ve arkadaşları; quadrotorun zamana bağlı olarak değişen yük durumunda quadrotor modelini ve denetimini incelemişlerdir. Quadrotor modelini zamanla değişen yük durumuna göre modellemişler ve denetim yöntemi olarak kayan kipli denetleyici(KKD) yapısını tasarlamışlardı[[7]. Gan Y. ve arkadaşları; önceden tanımlanmış bir yörüngeye, asılı yükü götüren bir quadrotorun doğrusal olmayan geri adımlamalı denetleyici(GAD) ile denetimini incelemişlerdir. Önerilen denetim performansını ve geçerliliğini belirlemek için deneysel sonuçlara yer vermişlerdir[8]. Marcos A. ve arkadaşları; bir grup quadrotoru kendi haline bırakmışlar ve takip probleminin oluşumunu incelemişlerdir. Çalışmalarında Parrot AR.Drone 2.0 isimli quadrotor tipi dronları kullanmışlardır. Önerilen denetim stratejisi, lider dronun önceden belirlenmiş bir uçuş yörüngesine asimptotik olarak yakınlaşmasına izin verirken, takip̧̧i dronların asimptotik olarak lider konumuna ve sabit bir oluşum vektörü tarafindan tanımlanan kendi yörüngelerine asimptotik olarak yakınlaşmasına izin vermektedir[9]. Liang Y. ve arkadaşları; insansız hava araçları(IHA) filolarının oluşumu için parametrik olarak belirsiz adaptif KKD metodunu önermişlerdir. Her bir quadrotorun atalet matrisi parametrelerini online olarak tahmin etmek için adaptif bir yasa tanımlamışlar ve tahmin edilen değerler takip hatasını düzgün bir şekilde asimtotik olarak sıfira yaklaştırmayı garantileyen yasayı KKD'de kullanmışlardır. Belirsiz koşullar ve sistemdeki dış rahatsızlıklar altında yapılan benzetim ile önerilen yöntemin İHA filolarının oluşumunu kararlı bir tutum ve hız senkronizasyonu ile gerçekleştirebileceğini göstermişlerdir[10]. Xuerui W. ve arkadaşları; quadrotorun hata toleranslı denetim problemi için yapılan uygulama ile kayan kipli hata gözlemleyicisi (INDI-SMC/SMDO) tarafindan yapılan artımlı kayan kipli denetim sürüşünü önermişlerdir. Literatürde yer alan modele dayalı, doğrusal olmayan ters çevrim(NDI) yerine sensöre dayalı artımlı doğrusal olmayan ters çevrim(INDI) yapısına dayanan kayan kipli hata gözlemcisi tasarlanarak kapalı döngü sistemindeki belirsizlikleri ve denetimin model bağımlılı̆̆ını azaltmışlardır. $\mathrm{Bu}$ yöntemi quadrotora uyguladıkları zaman gerçek uçuş testleri ve benzetim çalışmaları, eyleyici hataları, rüzgar etkisi ve model belirsizliklerinin varlığı durumunda SMC/SMDO'ya dayalı INDI performans ve denetim sağlamlığı bakımından SMC/SMDO'ya dayalı NDI yapısına göre daha iyi olduğunu göstermiş̧tir[11]. Ling Z. ve arkadaşları çalışmalarında; çift kapalı döngü stratejisine dayanan rüzgar bozucularına maruz kalmış quadrotorun durum denetimini incelemişlerdir. Çift kapalı döngü denetimi ile aktif bozucu reddetme denetimi ve integral kayan kipli denetimi birleştirerek önerdikleri denetim stratejisi ile quadrotorun rüzgar bozucu ile başa çıkabildiğini göstermişlerdir[12]. Hadi R. ve Sima A. çalışmalarında; quadrotor tipi insansız hava aracının tutum ve pozisyon denetimi için sinirsel ağ tabanlı kayan kipli denetim tasarımını gerçekleştirmişler ve quadrotorun dış bozuculara ve parametrik belirsizliklere maruz kaldığı durumda tutum ve pozisyon denetimi için yeni bir yöntem önermişlerdir. Bu yöntem sinirsel ağ tabanlı adaptif şema ile kayan kipli denetimin avantajlarını koruyan bir birleşimden meydana gelmektedir[13]. Fakui W. ve arkadaşları; bir insansız hava aracı türü olan mikro quadrotorun örnekleme geri bildirim vasıtasıyla ayrık denetim algoritması üzerinde çalışmışlardır. Benzetim çalışmaları sonucunda tasarlanan ayrık denetim ile endüstriyel uygulamalarda mikro quadrotorun ideal uçuş denetimi durumuna ulaşabileceğini göstermişlerdir[14]. Xiaobo L. ve arkadaşları çalışmalarında, dinamik yüzey denetimi ve ikinci dereceden kayan kipli bozucu gözlemcisi kullanarak quadrotorlar için ayrıştırıcı izleme denetleyicisini önermişlerdir. Makalede kullanılan dinamik yüzey denetimi orjinal alçak geçiren filtre yerine kayan kipli farklılaştırıcı kullanılarak iyileştirilmiş ve sistem belirsizlikleri ile dış bozucuların etkisini azaltmak için ikinci dereceden kayan kipli bozucu gözlemleyicisi kullanılmıştır. Ayrıca kararlılık analizi için bazı denetim değişkenlerinde basitleştirme yapmışlardır[15].

$\mathrm{Bu}$ çalı̧̧mada quadrotorun matematiksel modeli elde edilerek Matlab-Simulink ortamında benzetim modeli oluşturulmuş ve iki farklı denetim yöntemi model üzerinde test edilmiştir. Quadrotorun açısal durum ve yükseklik denetimine yönelik olarak KKD, GAD yöntemleri uygulanmış ve denetim performansları doğrultusunda kıyaslanmıştır. Denetleyicilerin denetim performansları quadrotorun denetimi yapılan yuvarlanma, yunuslama ve yönelme açıları ile yükseklik denetimi için ayrı ayrı incelenerek yerleşme zamanları hesaplanmış ve denetim yönteminden elde edilen sonuçların istenilen ölçütleri sağladı̆̆ı, quadrotorun doğrusal olmayan bir yapıda olmasına rağmen denetim başarımının yeterli olduğu görülmüştür.

Çalışmanın takip eden bölümleri şu şekilde düzenlenmiştir: İkinci bölümde quadrotorun matematiksel olarak incelemesi yapılmış, üçüncü bölümde denetim yöntemlerinin matematiksel ifadesi ve Matlab-Simulink modeline nasıl uygulanacağı anlatılmış, dördüncü bölümde benzetim çalışması ve test sonuçları üzerinde durulmuş, beşinci bölümde elde edilen sonuçların karşılaştırması yapılarak denetim yöntemlerinin performansları sunulmuştur. 


\section{Quadrotorun Matematiksel Modellenmesi}

Quadrotorun matematiksel modelinin elde edilmesinde araç üç boyutlu ortamda hareket eden katı bir cisim olarak kabul edilir. Cismin gövdesine uygulanan tork ve kuvvetler bu kabule göre elde edilmektedir. Dinamik ve kinematik modellerin oluşturulmasıyla elde edilen matematiksel model sistem davranışının zamanla değişimini açıklayabilmek için kullanılır. Matematiksel modelin elde edilmesinde kullanılan bazı sembol ve açıklamaları semboller listesinde verilmiştir.

\subsection{Kinematik model}

Quadrotorun kinematik modelinin elde edilmesinde, öncelikle kullanılacak koordinat noktaları belirlenir. Bu koordinatlar Şekil 1'de yer koordinat referansı $E_{x}, E_{y}, E_{z}$ eksenleri, gövde koordinat referansı $B_{x}, B_{y}, B_{z}$ eksenleri olarak gösterilmektedir. Yer koordinat ekseni ile gövde koordinat ekseni arasındaki mesafe kesin olarak $r=$ $\left[\begin{array}{lll}x & y & z\end{array}\right]^{T}$ ile tanımlanır.

Euler dönüşümü kullanılarak elde edilen $\mathrm{R}$ dönüşüm matrisi ile quadrotorun yer eksenine göre yönelimi elde edilmiş olmaktadır. Quadrotorun yönelimi sırasıyla $B_{x}, B_{y}, B_{z}$ eksenlerini temsil eden yuvarlanma, yunuslama ve yönelme açıları kullanılarak açıklanmaktadır[16].

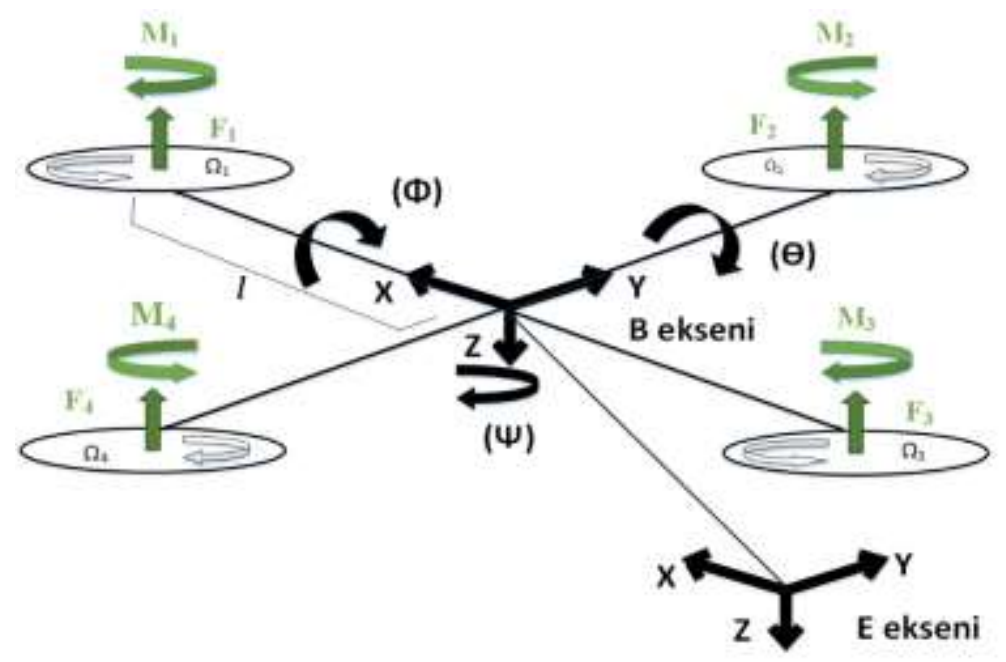

Şekil 1. Quadrotor koordinat eksenleri

$B_{x}, B_{y}, B_{z}$ eksenlerindeki dönüşüm matrisleri matris çarpımı yapılarak transpozu alınır ve denklem (1)'de görüldüğü gibi dönüşüm matrisi elde edilir[17].

$R_{i}^{b}=R(\Phi, x) * R(\theta, y) * R(\Psi, z)$

$R_{i}^{b}=\left[\begin{array}{ccc}1 & 0 & 0 \\ 0 & \cos \Phi & -\sin \Phi \\ 0 & \sin \Phi & \cos \Phi\end{array}\right]\left[\begin{array}{ccc}\cos \theta & 0 & \sin \theta \\ 0 & 1 & 0 \\ -\sin \theta & 0 & \cos \theta\end{array}\right]\left[\begin{array}{ccc}\cos \Psi & -\sin \Psi & 0 \\ \sin \Psi & \cos \Psi & 0 \\ 0 & 0 & 1\end{array}\right]$

$R=\left(R_{i}^{b}\right)^{T}=R_{b}^{i}$

$\mathrm{R}=\left[\begin{array}{ccc}\cos \Psi \cos \theta & \cos \Psi \sin \theta \sin \Phi-\sin \Psi \cos \Phi & \cos \Psi \sin \theta \cos \Phi+\sin \Psi \sin \Phi \\ \sin \Psi \cos \theta & \sin \Psi \sin \theta \sin \Phi+\cos \Psi \cos \Phi & \sin \Psi \sin \theta \cos \Phi-\sin \Phi \cos \Psi \\ -\sin \theta & \cos \theta \sin \Phi & \cos \theta \cos \Phi\end{array}\right]$

\subsection{Dinamik model}

Quadrotorun dinamik modelinin elde edilmesi, dönme hareket denklemleri ve dönüşüm hareket denklemleri olmak üzere iki ana bölüm altında incelenir.

Dönme hareket denklemleri Newton-Euler yöntemi kullanılarak $B$ eksen takımından türetilen hareket denklemleridir ve $B$ eksen takımına etki eden moment ifadesi aşağıdaki gibi yazılır. 
$\mathrm{J} \dot{\omega}+\omega \times \mathrm{J} \omega+\omega x\left[\begin{array}{lll}0 & 0 & J_{r} \Omega_{r}\end{array}\right]^{T}=M_{B}$

$M_{B}$ B eksen takımına etki eden moment, J quadrotorun diyagonal atalet matrisi, $\omega$ quadrotorun açısal hız vektörü, $\dot{\omega}$ quadrotorun açısal ivme vektörü, $J_{r}$ rotor ataleti, $\Omega_{r}$ quadrotorun z eksenindeki dönüsel dengesizliği olarak ifade edilmektedir. Denklem (2) ile verilen quadrotor momenti, rotorlar tarafindan üretilen moment ve aerodinamik kuvvetler olmak üzere iki fiziksel etkiyle tanımlanır. Rotorlar tarafından üretilen itki kuvveti döndürme etkisini gerçekleştirir ve böylece kuvvet ile kuvvet kolu çarpımı sonucunda moment etkisi ortaya çıkar. Rotorlar tarafindan üretilen kuvvet ve moment denklemleri aşağıdaki gibi ifade edilir.

$F_{i}=b \Omega_{i}^{2}$

$M_{i}=b l \Omega_{i}^{2}$

$F_{i}$ i'inci rotorun itki kuvveti, $b$ aerodinamik kuvvet sabiti, $\Omega_{i}$ i'inci rotorun açısal hızı, $M_{i}$ i'inci rotorun momenti, $l$ quadrotorun merkezinden rotora olan uzaklığı ifade etmektedir. Rotorlar tarafindan üretilen moment ve kuvvetlerin etkisi quadrotor üzerinde incelenirse $x, y, z$ eksenleri üzerindeki momentler aşağıdaki gibi yazılır.

$M_{B}=\left[\begin{array}{l}M_{x} \\ M_{y} \\ M_{z}\end{array}\right]=\left[\begin{array}{c}l b\left(-\Omega_{2}^{2}+\Omega_{4}^{2}\right) \\ l b\left(\Omega_{1}^{2}-\Omega_{2}^{2}\right) \\ d\left(\Omega_{1}^{2}-\Omega_{2}^{2}+\Omega_{3}^{2}-\Omega_{4}^{2}\right)\end{array}\right]$

$M_{x}$ x eksenine etki eden moment, $M_{y}$ y eksenine etki eden moment, $M_{z} \mathrm{z}$ eksenine etki eden moment, $d$ dönüsel dengesizlik moment sabiti olarak ifade edilir. Dönüşüm hareket denklemi, Newton'un ikinci yasasına dayanarak sabit eksen takımına göre aşağıdaki gibi yazılır.

$m \ddot{r}=\left[\begin{array}{c}0 \\ 0 \\ m g\end{array}\right]+R F_{B}$

Burada $F_{B}$ yerçekiminden bağımsız olarak quadrotor rotorlarının toplam itki kuvveti, $m$ quadrotorun kütlesi, $\ddot{r}$ Newton'un ikinci yasasında yer alan ivme, $R$ dönüşüm matrisini ifade etmektedir. Toplam itki kuvveti aşağıdaki gibi yazılır.

$F_{B}=\left[\begin{array}{c}0 \\ 0 \\ -b\left(\Omega_{1}^{2}+\Omega_{2}^{2}+\Omega_{3}^{2}+\Omega_{4}^{2}\right)\end{array}\right]$

\subsection{Quadrotor denetim girişleri}

Denetim giriş vektörü $T$, quadrotorun $x, y, z$ eksenlerinde meydana gelen itki kuvveti değişimlerini ifade eder. Quadrotorun yükselme, alçalma ve askıda kalması için gerekli olan itki kuvvetini denetim girişi $T_{z}, x$ ekseni için denetim girişi $T_{\phi}, y$ ekseni için denetim girişis $T_{\theta}, z$ ekseni için denetim girişi $T_{\psi}$ ile aşağıdaki gibi ifade edilir.

$T=\left[\begin{array}{lll}T_{Z} & T_{\Phi} T_{\theta} T_{\Psi}\end{array}\right]$

$T_{z}=b\left(\Omega_{1}^{2}+\Omega_{2}^{2}+\Omega_{3}^{2}+\Omega_{4}^{2}\right)$

$T_{\Phi}=b\left(-\Omega_{2}{ }^{2}+\Omega_{4}{ }^{2}\right)$

$T_{\theta}=b\left(\Omega_{1}{ }^{2}-\Omega_{3}{ }^{2}\right)$

$T_{\Psi}=d\left(-\Omega_{1}{ }^{2}+\Omega_{2}{ }^{2}-\Omega_{3}{ }^{2}+\Omega_{4}{ }^{2}\right)$

Quadrotorun dönme hareket denklemleri; quadrotorun açı değişimlerinden sorumlu olan ve denklem (9), (10), (11)'de açıkça yazılan momentleri aşağıdaki gibi matris formunda yazılarak denklem (12) elde edilir.

$M_{B}=\left[\begin{array}{c}l T_{\Phi} \\ l T_{\theta} \\ T_{\Psi}\end{array}\right]$ 
Denklem (12) denklem (2)'de verilen B eksen takımına etki eden moment eşitliğinde yerine konur ve genişletilerek yeniden yazılırsa quadrotorun açısal ivmeleri aşağıdaki gibi elde edilir.

$\ddot{\Phi}=\dot{\Psi} \dot{\theta}\left(\frac{I_{y y}-I_{z z}}{I_{x x}}\right)-\frac{\mathrm{J}_{\mathrm{r}}}{I_{x x}} \dot{\theta} \Omega_{\mathrm{r}}+\frac{l}{I_{x x}} T_{\Phi}$
$\ddot{\theta}=\dot{\Psi} \dot{\Phi}\left(\frac{I_{z z}-I_{x x}}{I_{y y}}\right)+\frac{\mathrm{J}_{\mathrm{r}}}{I_{y y}} \dot{\Phi} \Omega_{\mathrm{r}}+\frac{l}{I_{y y}} T_{\theta}$
$\ddot{\Psi}=\dot{\theta} \dot{\Phi}\left(\frac{I_{x x}-I_{y y}}{I_{z z}}\right)+\frac{l}{I_{z z}} T_{\Psi}$

$\ddot{\Phi}$ yuvarlanma açısı ivmesi, $\ddot{\theta}$ yunuslama açısı ivmesi, $\ddot{\Psi}$ yönelme açısı ivmesi, $\dot{\Phi}$ yuvarlanma açısı açısal hızı, $\dot{\theta}$ yunuslama açısı açısal hızı, $\dot{\Psi}$ yönelme açısı açısal hızı $I_{x x}$ x eksenindeki atalet momenti, $I_{y y}$ y eksenindeki atalet momenti, $I_{z z} \mathrm{z}$ eksenindeki atalet momenti olarak ifade edilir. Denklem (8) ile verilen itki kuvveti denetim girişi, denklem (6)'da yerine yazılarak elde edilen yeni ifadeyi, Newton'un ikinci kanunu ile yazılan dönüşüm hareket denklemi denklem (5)'te yerine konularak yazılır ve gerekli işlemler yapılırsa quadrotorun $x, y, z$ eksenlerindeki ivmeler aşağıdaki gibi elde edilir.

$\ddot{x}=\frac{-T_{z}}{m}(\cos \Psi \sin \theta \cos \Phi+\sin \Psi \sin \Phi)$

$\ddot{y}=\frac{-T_{z}}{m}(\sin \Psi \sin \theta \cos \Phi-\sin \Phi \cos \Psi)$

$\ddot{z}=g-\frac{T_{z}}{m}(\cos \theta \cos \Phi)$

Burada $\ddot{x}, \ddot{y}$ ve $\ddot{z}$ sırasıyla $x, y$ ve $z$ eksenlerindeki ivme, $\Phi$ yuvarlanma açısı, $\theta$ yunuslama açısı, $\Psi$ yönelme açısı olarak ifade edilir. Bir quadrotorun matematiksel modelinin oluşturulmasında dönme ve dönüşüm denklemlerine ihtiyaç duyulmaktadır. Dönme denklemleri kullanılarak quadrotorun açısal hızları elde edilirken dönüşüm denklemleri ile quadrotorun $x, y, z$ eksenlerinde oluşan ivme denklemleri elde edilmiştir. Böylece quadrotorun yön, hız ve ivme verilerine ulaşılabilmektedir.

\section{Denetim Yapısı}

Bu bölümde quadrotorun $x, y, z$ eksenlerindeki yuvarlanma, yunuslama, yönelme açıları ve yüksekliğinin denetimi için uygulanan denetim yöntemleri ele alınmıştır. Bu denetim yöntemleri aşağıda belirtildiği gibi GAD ve KKD olmak üzere quadrotor üzerinde uygulanması Şekil 2'de gösterilen quadrotor blok diyagramı ile ifade edilmiştir.

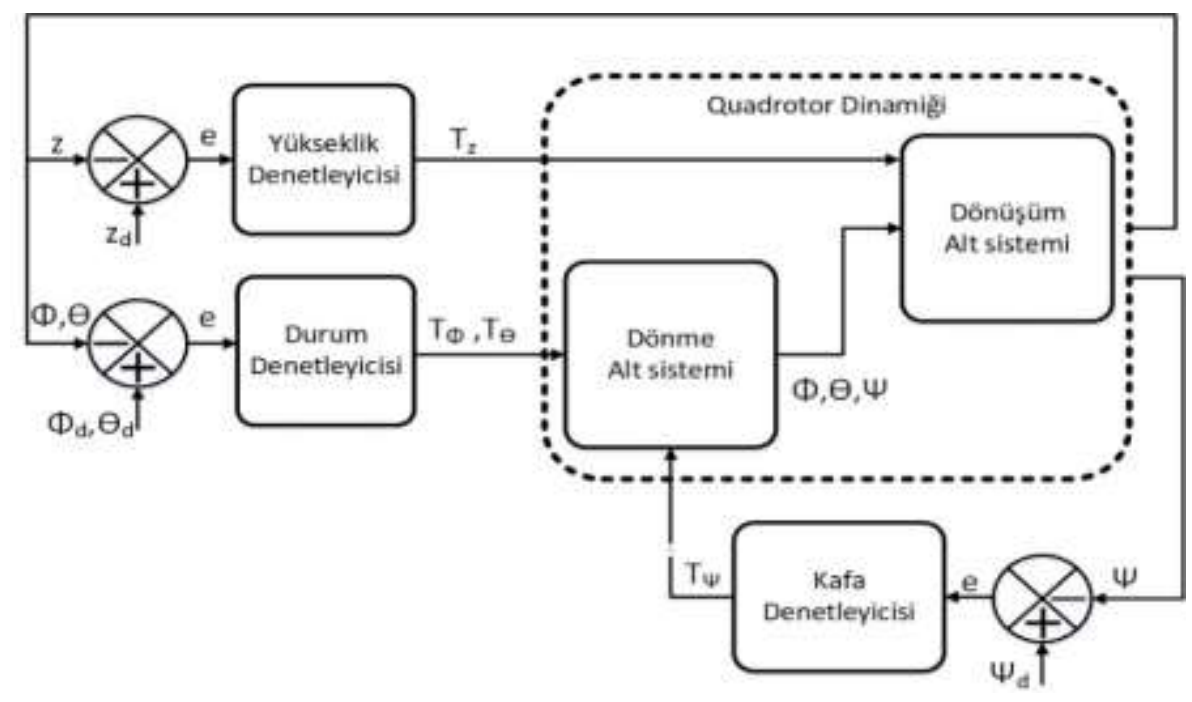

Şekil 2. Quadrotor blok diyagramı 


\subsection{Kayan kipli denetleyici}

KKD'de Lyapunov kararlılık metodu kullanılarak doğrusal olmayan sistemin denetimi daha yüksek mertebedeki bir sistemin birinci mertebede bir sisteme dönüştürülmesiyle sağlanır. Bu sayede kolay ve dayanıklı olan denetim yöntemi uygulanır[18].

KKD süreksiz yapıda olan bir denetim yöntemi olmasından dolayı denetim yüzeyi üzerinde süreklilik denetimi elde edilemez. Bu nedenle denetleyici tarafından sistem durumu kayma yüzeyinin dışına çıktığında ani bir denetim işareti üretilir ve denetim durumunu tekrar yüzey üzerine getirmeye çalışır. Denetim sistemi kayan yüzey üzerinde denetimi sağlamak için çok kısa sürede çok sayıda anahtarlama yaparak yön değiştirir. Bu yön değiştirme işaretleriyle sistem denetimi sağlanır. KKD'nin kayma yüzeyinde oluşan yön değiştirme hareketleri Şekil 3’te gösterilen ok yönlerinde olmaktadır[19].

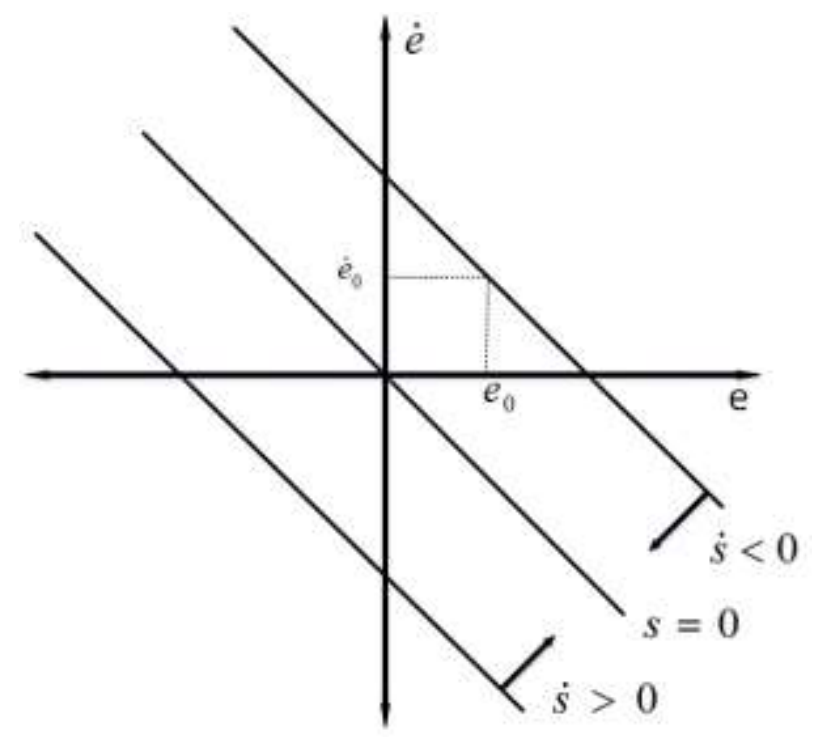

Şekil 3. KKD kayma yüzeyi $(\mathrm{s}=0)$

KKD yapısı düzeltici denetim ve eşdeğer denetim olmak üzere denklem (15)'te ifade edildiği gibi iki parçadan oluşur. Düzeltici denetim kayma yüzeyine ulaşmak için kayma yüzeyinde meydana gelen sapmaları telafi eder. Eşdeğer denetim ise kayma yüzeyinde tutunmak için kayan yüzeyin türevini sıfira eşit hale getirir. Şekil 4'te KKD'nin quadrotor üzerine uygulanışının blok diyagramı görülmektedir[20].

$U(t)=U_{c}(t)+U_{e}(t)$

Burada; $U(t)$ denetim yasasını, $U_{c}(t)$ düzeltici denetimi, $U_{e}(t)$ eşdeğer denetimi ifade etmektedir.

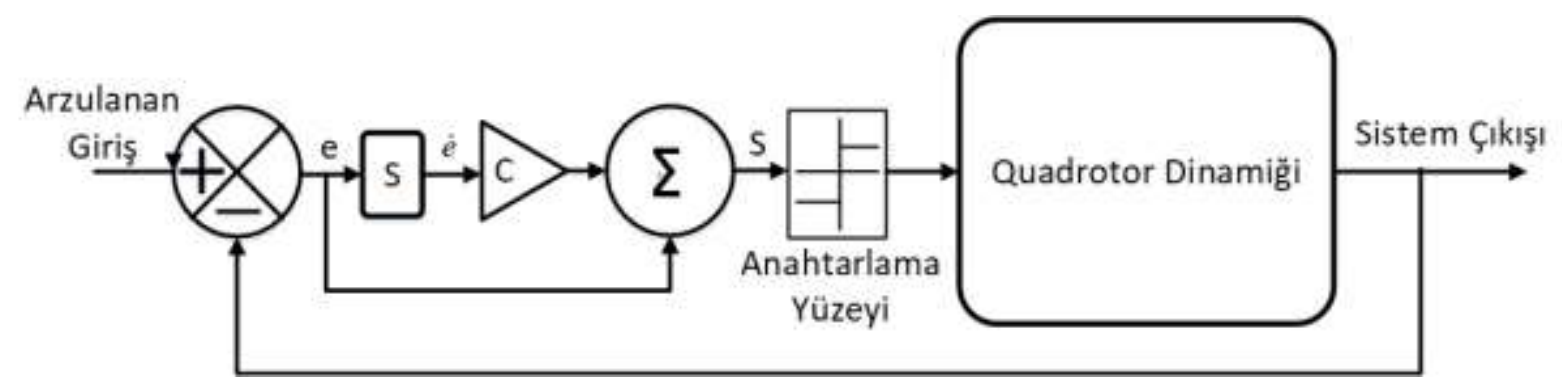

Şekil 4. KKD blok diyagramı

Quadrotorun KKD ile denetim girişinin elde edilmesi için ilk olarak arzulanan yuvarlanma açısından $\left(\phi_{d}\right)$ gerçek yuvarlanma açısı $(\phi)$ çıkartılarak hata hesaplanır, 
$e=\Phi_{d}-\Phi$

KKD referans yüzeyi tanımlanır,

$s=c_{1} e+\dot{e}$

$\dot{s}=c_{1} \dot{e}+\ddot{e}$

$\dot{s}=c_{1}\left(\dot{\Phi}_{d}-\dot{\Phi}\right)+\left(\ddot{\Phi}_{d}-\ddot{\Phi}\right)$

Lyapunov fonksiyonu denklem (18) seçilir ve Lyapunav fonksiyonuna dayanan KKD için üstel erişim yasası denklem (19) tanımlanır,

$V(e, s)=\frac{1}{2}\left(e^{2}+s^{2}\right)$

$\dot{s}=-k_{1} \operatorname{sgn}(s)-k_{2} s$

Burada $k_{1}$ ve $k_{2}$ pozitif denetim sabitleridir ve $\operatorname{sgn}(s)$ fonksiyonu kararlllığı sağlamak için denklem (20)'deki gibi tanımlanır.

$\operatorname{sgn}(s)=\left\{\begin{array}{cc}-1 & i \operatorname{ccin} s<0 \\ 1 & \text { için } s>0\end{array}\right.$

Yuvarlanma açısı denetim girişini oluşturmak için elde edilen denklem (17)'de $\ddot{\Phi}$ yerine eşiti olan denklem (13) yazılır ve $T_{\Phi}$ ifadesi çekilerek denklem (21) elde edilir.

$T_{\Phi}=\frac{1}{b_{1}}\left[c_{1}\left(\dot{\Phi}_{d}-\dot{\Phi}\right)+\ddot{\Phi}_{d}+a_{2} \dot{\theta} \Omega_{r}-a_{1} \dot{\theta} \dot{\Psi}-\dot{s}\right]$

Bu denklemde $c_{1}$ pozitif denetim sabitidir ve $b_{1}=\frac{l}{I_{x x}}, a_{1}=\frac{I_{y y}-I_{z z}}{I_{x x}}, a_{2}=\frac{J_{r}}{I_{x x}}$

Yunuslama, yönelme açıları denetim girişleri ve yükseklik denetim girişi benzer işlemler uygulanarak elde edilebilir. Yunuslama açısı denetim girişi;

$T_{\theta}=\frac{1}{b_{2}}\left[c_{2}\left(\dot{\theta}_{d}-\dot{\theta}\right)+\ddot{\theta}_{d}-a_{4} \dot{\phi} \Omega_{r}-a_{3} \Phi \dot{\Psi}+k_{3} \operatorname{sgn}(s)+k_{4} s\right]$

$b_{2}=\frac{l}{I_{y y}}, a_{3}: \frac{I_{z z}-I_{x x}}{I_{y y}}, a_{4}: \frac{J_{r}}{I_{y y}}, c_{2}, k_{3}$, ve $k_{4}$ pozitif denetim sabitleri.

Yönelme açısı denetim girişi;

$T_{\Psi}=\frac{1}{b_{3}}\left[c_{3}\left(\dot{\Psi}_{d}-\dot{\Psi}\right)+\ddot{\Psi}_{d}-a_{5} \dot{\Phi} \dot{\theta}+k_{5} \operatorname{sgn}(s)+k_{6} s\right]$

Burada $c_{3}, k_{5}$ ve $k_{6}$ yönelme açısı için pozitif denetim sabitleridir ve $b_{3}=\frac{l}{I_{z z}}, a_{5}: \frac{I_{x x}-I_{y y}}{I_{z z}}$.

Yükseklik denetim girişi;

$T_{z}=\frac{m}{\cos \Phi \cos \theta}\left[c_{4}\left(\dot{z}_{d}-\dot{z}\right)+g-\ddot{z}_{d}+k_{7} \operatorname{sgn}(s)+k_{8} s\right]$

Burada $c_{4}, k_{7}$ ve $k_{8}$ KKD yükseklik denetimi pozitif denetim sabitleri.

\subsection{Geri adımlamalı denetleyici}

GAD'de amaç, durum denklemlerinin her adımda birbirini daha kararlı hale getirerek, denetimi yapılan sistemin ihtiyacı olan denetim işaretini üretmeye dayanmaktadır. Bu sayede her adımda kararlılığı daha iyi seviyeye getiren durum değişkenleri, sistemi kararlı hale getirmektedir[21].

GAD tasarımında quadrotorun matematiksel denklemlerinden elde edilen durum uzay modelinden yararlanılır[17]. Birinci adımda hata hesaplanır,

$e_{1}=u_{1_{d}}-u_{1}$ 
Burada $u$ ifadesi quadrotorun durum uzay modelinden gelmektedir. Lyapunov teorisi kullanılarak türevi negatif yarı tanımlı, kendisi pozitif tanımlı Lyapunov fonksiyonu denklem (26) seçilir ve türevi alınarak denklem (27) yazilir.

$$
\begin{aligned}
& V\left(e_{1}\right)=\frac{1}{2} e_{1}^{2} \\
& \dot{V}\left(e_{1}\right)=e_{1} \dot{e}_{1} \\
& \dot{V}\left(e_{1}\right)=e_{1}\left(\dot{u}_{1_{d}}-\dot{u}_{1}\right) \\
& \dot{V}\left(e_{1}\right)=e_{1}\left(\dot{u}_{1_{d}}-u_{2}\right)
\end{aligned}
$$

Kararlılığı sağlamak için sınırlama fonksiyonu $W_{1}(e)=-c_{1} e_{1}^{2}$ seçilir ve denklem (28) eşitliği yazılır,

$\dot{V}\left(e_{1}\right)=e_{1}\left(\dot{u}_{1_{d}}-u_{2}\right) \leq-c_{1} e_{1}^{2}$

Denklem (28)'de verilen $u_{2}$ değeri arzu edilen $\left(u_{2}\right)^{*}$ değerine hızlıca yakınsamasını sağlamak amacıyla arzu edilen sanal bir işaret denklem (29) seçilir ve ikinci bir döngü sağlanır. İkinci döngüde sanal denetim izleme hatası $e_{2}$ denklem (30) yazılır.

$$
\begin{aligned}
& \left(u_{2}\right)^{*}=\dot{u}_{1_{d}}+c_{1} e_{1} \\
& e_{2}=u_{2}-\left(u_{2}\right)^{*} \\
& e_{2}=u_{2}-\dot{u}_{1_{d}}-c_{1} e_{1}
\end{aligned}
$$

Denklem (30) ile verilen ifade Lyapunov fonksiyonunda yerine konur ve yeniden yazılır,

$\dot{V}\left(e_{1}\right)=e_{1} \dot{e}_{1}$

$\dot{V}\left(e_{1}\right)=e_{1}\left(\dot{u}_{1 d}-u_{2}\right)$

$\dot{V}\left(e_{1}\right)=e_{1}\left(\dot{u}_{1 d}-\left(e_{2}+\dot{u}_{1_{d}}+c_{1} e_{1}\right)\right.$

$\dot{V}\left(e_{1}\right)=-e_{1} e_{2}-c_{1} e_{1}^{2}$

İkinci döngü için yeni Lyapunov aday fonksiyonu seçilir ve Lyapunov fonksiyonunun zamana göre türevi alınarak aşağıdaki gibi elde edilir.

$$
\begin{aligned}
& V\left(e_{1}, e_{2}\right)=\frac{1}{2}\left(e_{1}^{2}+e_{2}^{2}\right) \\
& V\left(e_{1}, e_{2}\right)=V\left(e_{1}\right)+\frac{1}{2} e_{2}^{2} \\
& \dot{V}\left(e_{1}, e_{2}\right)=-e_{1} e_{2}-c_{1} e_{1}^{2}+e_{2}\left(\dot{u}_{2}-\ddot{u}_{1 d}-c_{1} \dot{e}_{1}\right)
\end{aligned}
$$

Pozitif tanımlı ikinci sınırlama fonksiyonu $W_{2}(e)=-e_{1} e_{1}^{2}-c_{2} e_{2}^{2}$ seçilerek denklem (34) eşitliği yazılır.

$\dot{V}\left(e_{1}, e_{2}\right)=-e_{1} e_{2}-c_{1} e_{1}^{2}+e_{2}\left(u_{6} u_{4} \mathrm{a}_{1}-\mathrm{a}_{2} u_{4} \Omega_{r}+\mathrm{b}_{1} T_{\Phi}-\ddot{u}_{1_{d}}-c_{1} \dot{e}_{1}\right) \leq-c_{1} e_{1}^{2}-c_{2} e_{2}^{2}$

Eşitsizlik çözülerek quadrotorun yuvarlanma açısı denetim girişi denklem (35) ile elde edilir.

$T_{\Phi}=\frac{1}{b_{1}}\left(-c_{2} e_{2}+e_{1}-u_{6} u_{4} \mathrm{a}_{1}+\mathrm{a}_{2} u_{4} \Omega_{r}+\ddot{u}_{1_{d}}+c_{1} \dot{u}_{1_{d}}-c_{1} u_{2}\right)$

Diğer denetim girişleri içinde benzer işlemler uygulanır ve aşağıdaki gibi yazılır.

Yunuslama açısı denetim girişi;

$T_{\theta}=\frac{1}{b_{2}}\left(-c_{4} e_{4}+e_{3}-u_{6} u_{2} \mathrm{a}_{3}-\mathrm{a}_{4} u_{2} \Omega_{r}+\ddot{u}_{3 d}+c_{3} \dot{u}_{3 d}-c_{3} u_{4}\right)$ 
Yönelme açısı denetim girişi;

$T_{\Psi}=\frac{1}{b_{3}}\left(-c_{6} e_{6}+e_{5}-u_{4} u_{2} \mathrm{a}_{5}+\ddot{u}_{5_{d}}+c_{5} \dot{u}_{5_{d}}-c_{5} u_{6}\right)$

Yükseklik denetim girişi:

$T_{z}=\frac{m}{\cos u_{1} \cos u_{3}}\left(-e_{7}+g-+\ddot{u}_{7 d}-c_{7} \dot{u}_{7 d}+c_{7} u_{8}+c_{8} e_{8}\right)$

\section{Benzetim Çalış̧asıs}

Quadrotorun benzetim çalışması Matlab/Simulink ortamında gerçekleştirilmiştir. Sistem; denetleyici ve quadrotor bloğu olarak Şekil 5'te verildiği gibi düşünülmüş, bölüm 2 ve 3 'te elde edilen matematiksel denklemlerden yararlanılarak Matlab/Simulink ortamında denetleyici ve quadrotor olmak üzere iki ayrı blok şeklinde Şekil 6'da görüldüğü gibi tasarlanmıştır. İki faklı denetleyici için ayrı ayrı denetleyici bloğu tasarlanarak, istenen açı ve yükseklik denetimleri Tablo 1'de verilen parametre değerlerine sahip quadrotor bloğu üzerinde test edilmiştir.

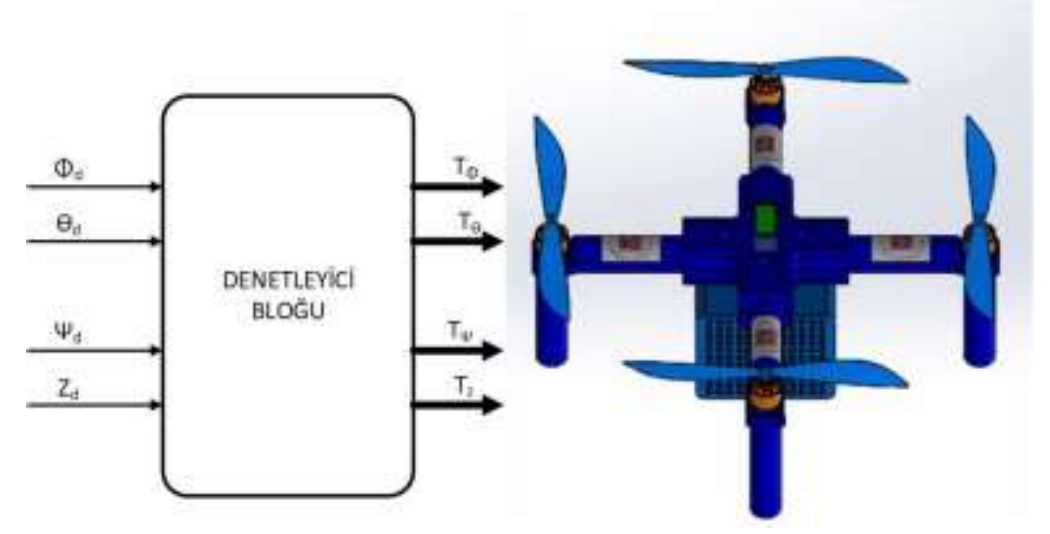

Şekil 5. Denetleyici bloğu ve quadrotor

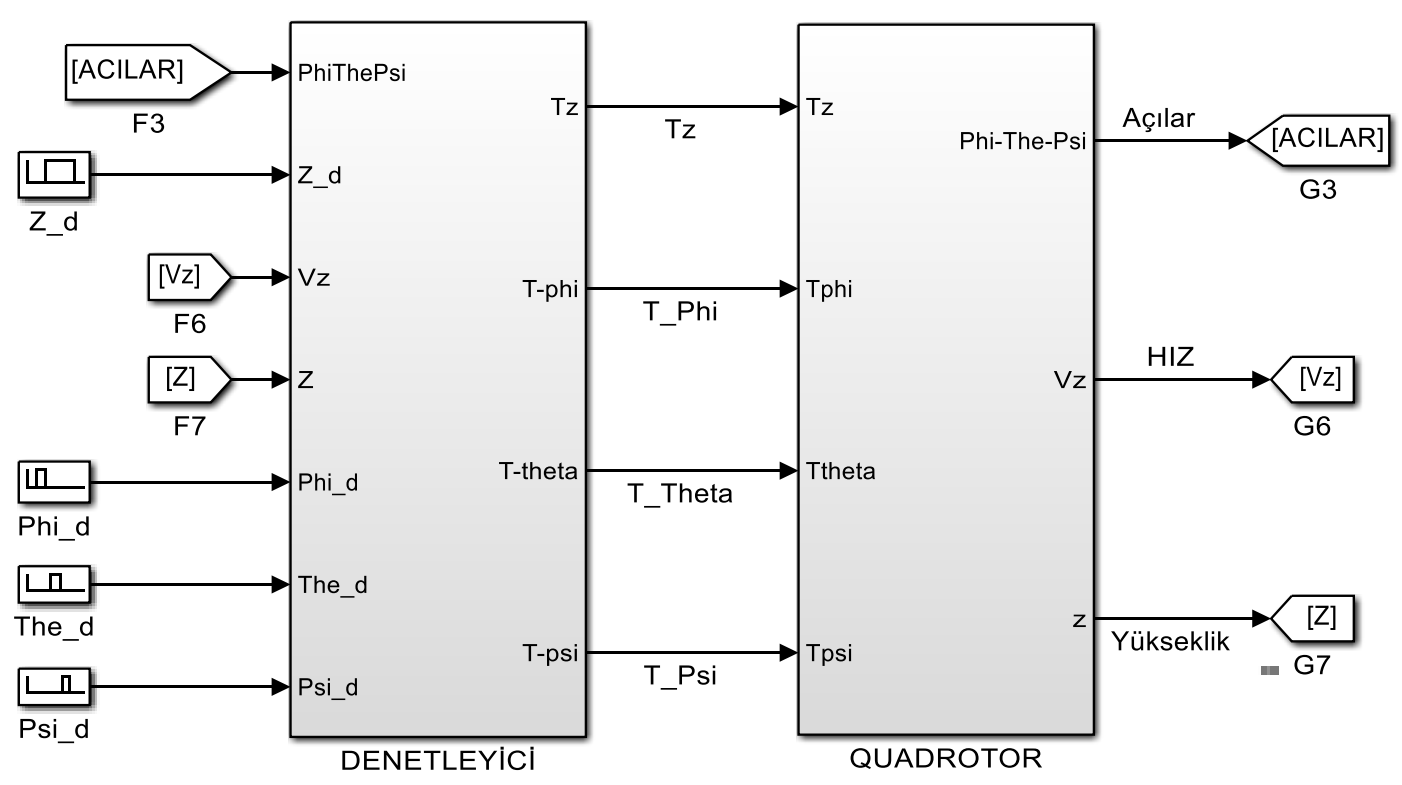

Şekil 6. Simulink modeli 
Tablo 1. Quadrotor parametreleri

\begin{tabular}{|c|c|c|}
\hline Parametre & Değer & Birim \\
\hline$I_{x x}$ & $7.5^{*} 10^{\wedge}(-3)$ & Kg. $\mathrm{m}^{2}$ \\
\hline$I_{y y}$ & $7.5^{*} 10^{\wedge}(-3)$ & $\mathrm{Kg} \cdot \mathrm{m}^{2}$ \\
\hline$I_{z z}$ & $1.3^{*} 10^{\wedge}(-2)$ & $\mathrm{Kg} \cdot \mathrm{m}^{2}$ \\
\hline $\mathrm{Jr}$ & $6.5^{*} 10^{\wedge}(-5)$ & $\mathrm{Kg} \cdot \mathrm{m}^{2}$ \\
\hline $\mathrm{b}$ & $3.13^{*} 10^{\wedge}(-5)$ & $\mathrm{N} \cdot \mathrm{s}^{2}$ \\
\hline $\mathrm{d}$ & $7.5^{*} 10^{\wedge}(-7)$ & $\mathrm{N} \cdot \mathrm{m} \cdot \mathrm{s}^{2}$ \\
\hline$l$ & 0.23 & $\mathrm{~m}$ \\
\hline $\mathrm{m}$ & 1.35 & $\mathrm{~kg}$ \\
\hline $\mathrm{g}$ & 9.81 & $\mathrm{~m} / \mathrm{sn}^{2}$ \\
\hline
\end{tabular}

\subsection{Kayan kipli denetleyici}

KKD ile quadrotorun yuvarlanma açısı, yunuslama açısı, yönelme açısı ve yükseklik denetimlerinde kullanılan denetim parametreleri Tablo 2'de verilmiş̧tir. Bu parametre değerleriyle benzetim modelinde quadrotor bloğuna KKD denetimi uygulanmış, denetimi yapılan yuvarlanma, yunuslama ve yönelme açılarına farklı zamanlarda değerler girilmiş ve bu açı değerlerinde kendisini sabitlemesi istenmiştir. Aynı şekilde yükseklik denetimi içinde $2 \mathrm{~m}$ yükseklikte durması istenmiştir. Benzetim çalışmasından elde edilen sonuç grafikleri Şekil 7'de verilmiş̧tir. Şekil 8'de ise, Şekil 7 ile verilen sonuçların geçici durum davranışları ayrıntılı olarak verilmiştir.

Tablo 2. KKD denetim parametreleri

\begin{tabular}{|c|c|c|c|}
\hline & $\mathrm{c}_{1}$ & $\mathrm{k}_{1}$ & $\mathrm{k}_{2}$ \\
\hline$\Phi$ & 4.68 & 1.99 & 1.80 \\
\hline$\theta$ & 20 & 0.8 & 0 \\
\hline$\Psi$ & 20 & 1.2 & 0 \\
\hline $\mathrm{z}$ & 6.68 & 2.66 & 6.64 \\
\hline
\end{tabular}
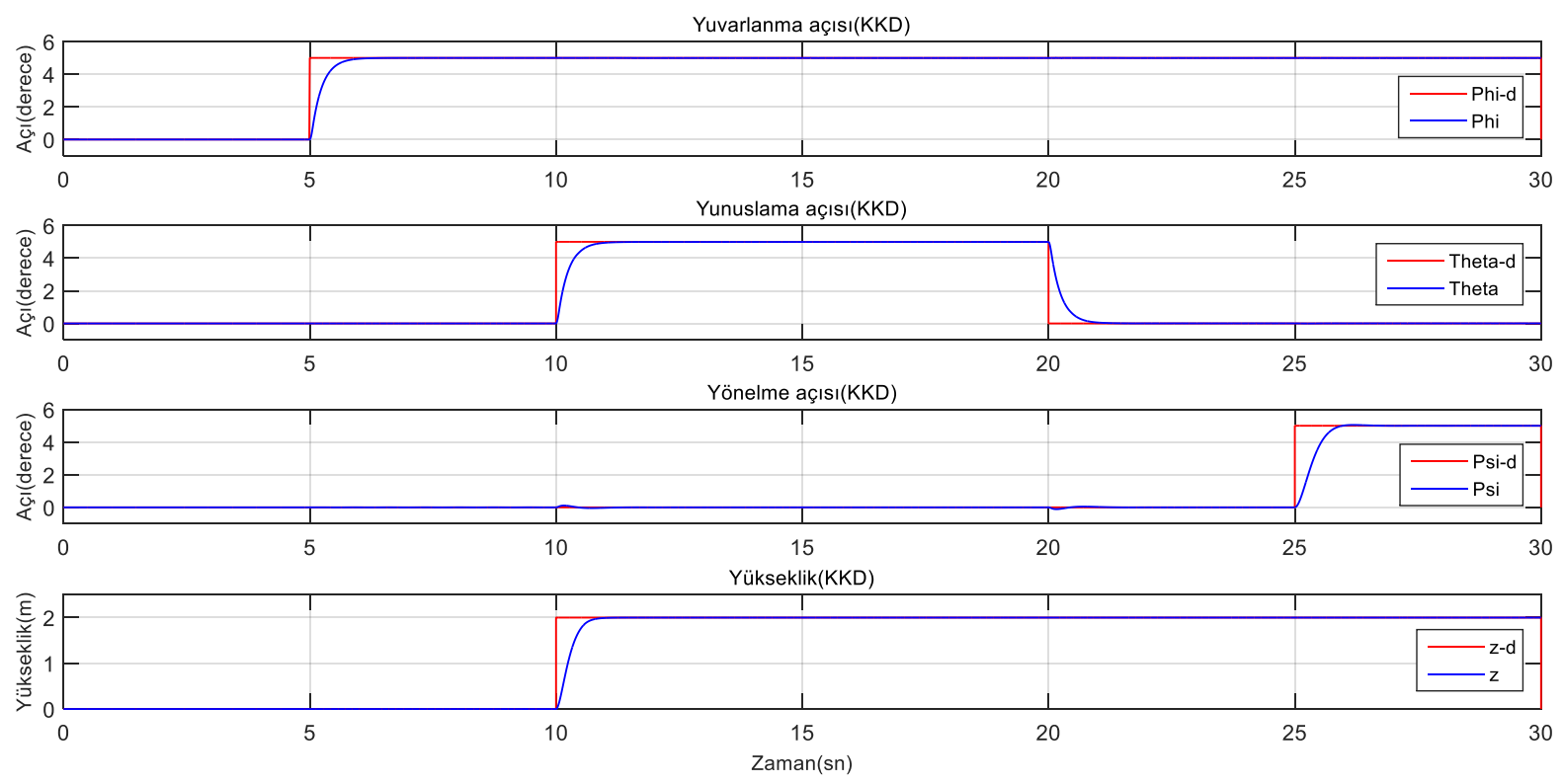

Şekil 7. KKD denetim sonuçları 

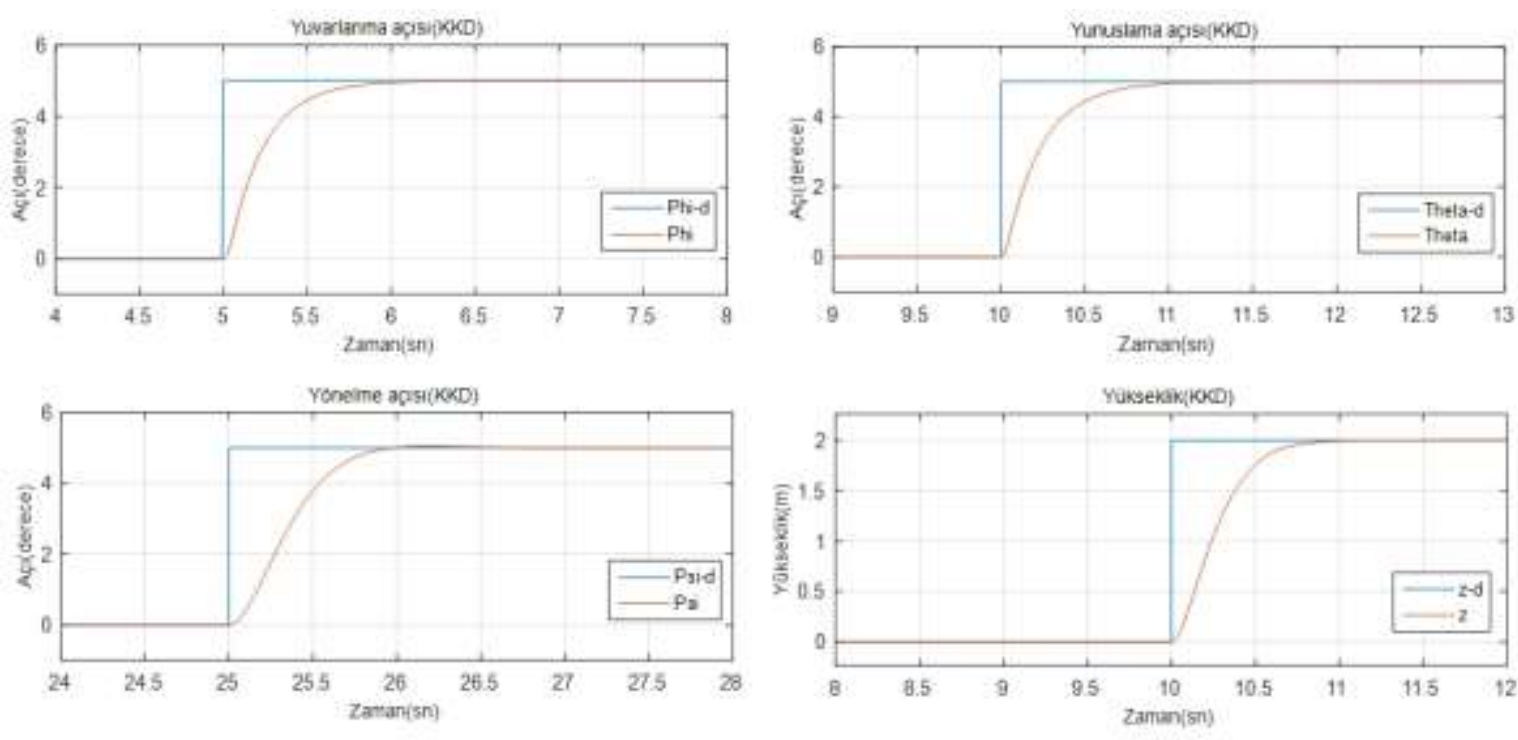

Şekil 8. KKD denetim sonuçlarının detaylandırılmış hali

Şekil 7'de verilen grafikte görüldüğü gibi sistem denetimi başarılı bir şekilde kararlılığı sağlamıştır. Basamak giriş işareti için yerleşme zamanları (\%2'lik bant aralığı için) Tablo 3 'te verildiği gibi elde edilmiştir. Yuvarlanma açısı denetimi için 5'inci saniyeden itibaren yuvarlanma açısını 5 dereceye, yunuslama açısı denetimi için 10 ve 20'inci saniye aralığında yunuslama açısını 5 dereceye, yönelme açısı denetimi için 25'inci saniyeden itibaren yönelme açısını 5 dereceye sabitlenmesi girdi olarak verilmiştir. Yükseklik denetimi için ise 10'uncu saniyeden itibaren 2 metre yükseklikte askıda kalması istenmiş, Şekil 7 ile verilen grafik incelendiğinde belirtilen zamanlarda sistemin denetim kararlılığını sağladığı görülmüştür.

Tablo 3. KKD yerleşme zamanları

\begin{tabular}{|c|c|c|c|c|}
\hline & $\Phi$ & $\theta$ & $\Psi$ & $\mathrm{Z}$ \\
\hline Yerleşme Zamanı(sn) & 0.86 & 0.87 & 0.85 & 0.91 \\
\hline
\end{tabular}

\subsection{Geri adımlamalı denetleyici}

GAD ile quadrotorun yuvarlanma açısı, yunuslama açısı, yönelme açısı ve yükseklik denetimlerinde kullanılan denetim parametreleri Tablo 4'te verilmiştir. Simulink modeli üzerinde GAD için tasarlanan bu parametreler kullanılarak quadrotor denetimini gerçekleştirilmiş ve elde edilen sonuç grafikleri Şekil 9 ile verilmiştir. Şekil 9'da verilen grafik Şekil 10 ile detaylı olarak gösterilmiştir.

Tablo 4. GAD denetim parametreleri

\begin{tabular}{|c|c|c|}
\hline & $\mathrm{c}_{1}$ & $\mathrm{c}_{2}$ \\
\hline$\Phi$ & 5.52 & 3.40 \\
\hline$\theta$ & 5.52 & 3.40 \\
\hline$\Psi$ & 10.57 & 3.71 \\
\hline $\mathrm{z}$ & 2.80 & 11.40 \\
\hline
\end{tabular}



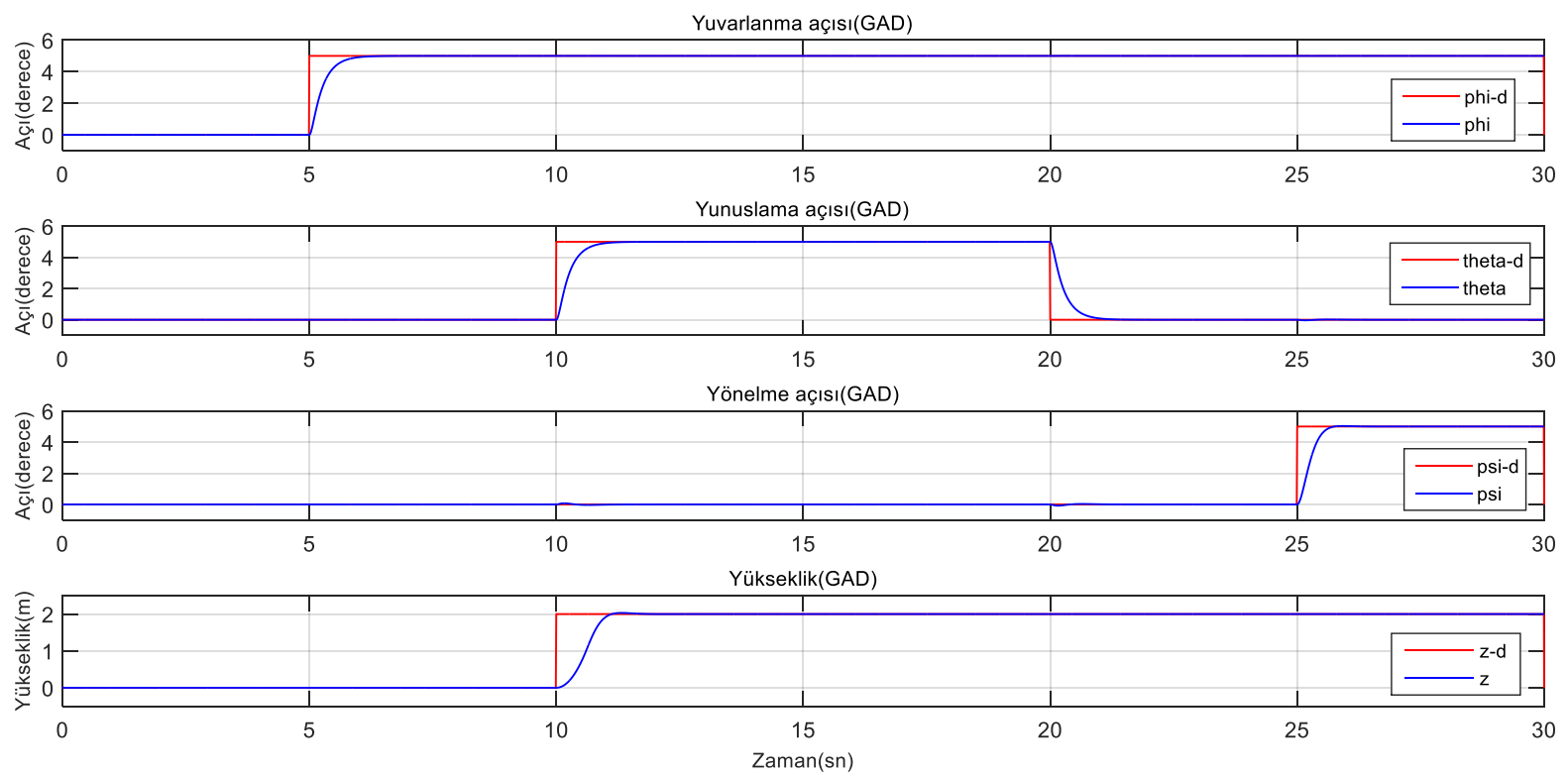

Şekil 9. GAD denetim sonuçları
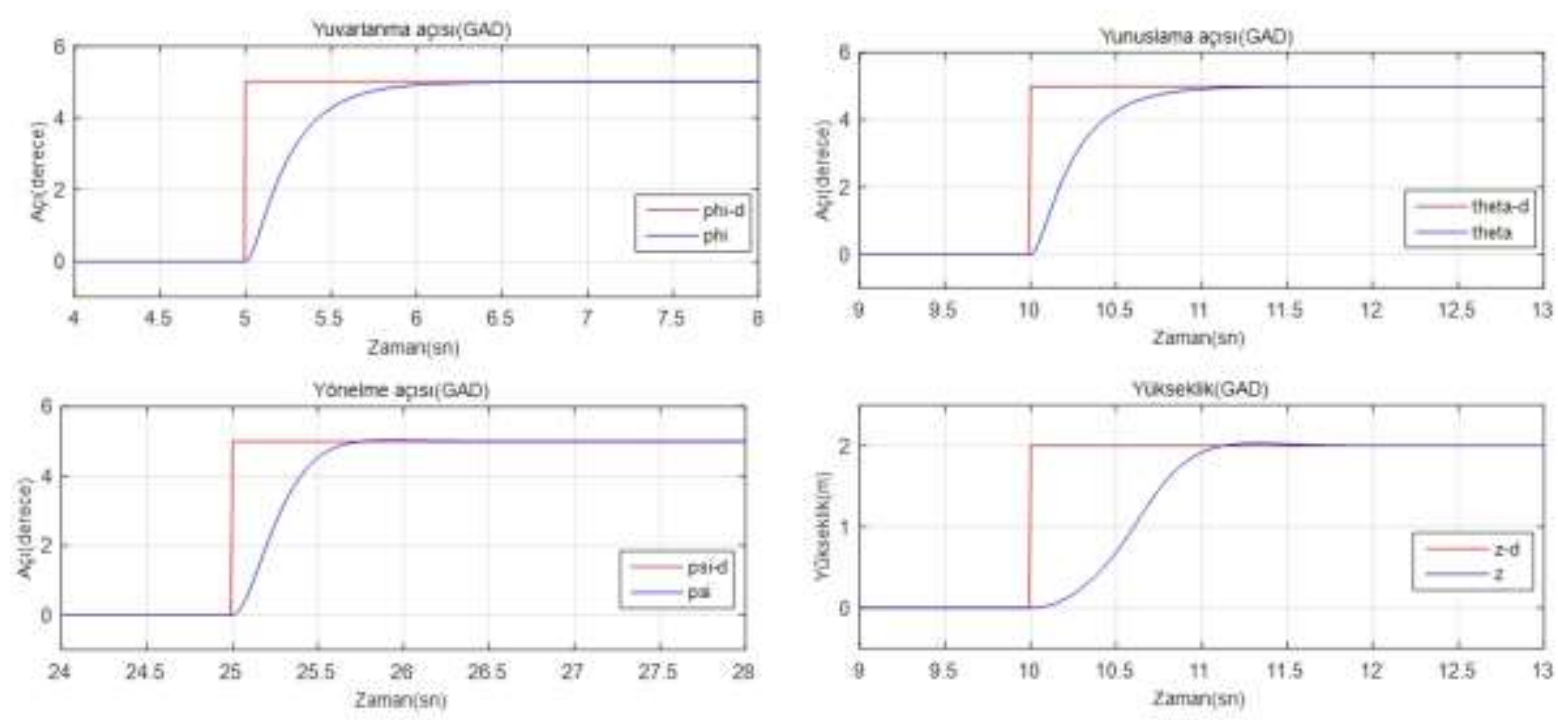

Şekil 10. GAD denetim sonuçlarının detaylandırılmış hali

Şekil 9 ile verilen sonuçlar incelendiğinde GAD ile quadrotorun yuvarlanma, yunuslama, yönelme açılarının ve yükseklik denetimlerinin basamak referanslarını başarılı bir şekilde izlediği görülmektedir. Basamak giriş referansına ilişkin yerleşme süreleri de Tablo 5 ile sunulmuştur. Ancak yerleşme zamanları incelendiğinde yuvarlanma açısı, yunuslama açısı ve yükseklik denetimlerinde GAD denetiminin KKD denetim başarısına göre cevap verme süresinin daha uzun olduğu görülmüştür.

Tablo 5. GAD yerleşme zamanları

\begin{tabular}{|c|c|c|c|c|}
\hline & $\Phi$ & $\theta$ & $\Psi$ & $\mathrm{Z}$ \\
\hline Yerleşme Zamanı(sn) & 0.95 & 0.96 & 0.64 & 1.05 \\
\hline
\end{tabular}




\section{Sonuç}

KKD ve GAD yöntemleri kullanılarak doğrusal olmayan sistemler için kullanılan doğrusal olmayan bu iki denetleyiciden quadrotor denetimi için en iyi denetim başarısını verecek denetleyici elde edilmeye çalışılmış ve yapılan benzetim çalışması sonucunda \%2'lik bant için, yerleşme zamanları Tablo 6 ile sunulmuştur.

Tablo 6. Quadrotor denetimi yerleşme zamanları karşılaştırması

\begin{tabular}{|c|c|c|c|}
\hline & KKD & GAD & En başarılı denetim yöntemi \\
\hline$\Phi$ & 0.86 & 0.95 & KKD \\
\hline$\theta$ & 0.87 & 0.96 & KKD \\
\hline$\Psi$ & 0.85 & 0.64 & GAD \\
\hline $\mathrm{Z}$ & 0.91 & 1.05 & KKD \\
\hline
\end{tabular}

Tablo 6 ile verilen denetim sonuçları incelendiğinde quadrotor modeli üzerinde test edilen KKD, GAD yöntemlerinin denetim başarısı yerleşme zamanları birbirine yakın sonuçlar verdiği gözlemlenmiştir. Ancak KKD denetim başarısı GAD denetim başarısından yuvarlanma açısı, yunuslama açısı ve yükseklik denetimlerinde yaklaşık 0.1 sn aralığında daha iyi sonuç verdiğgi, yönelme açısında ise GAD’nin KKD'den 0.21 sn daha başarılı olduğu gözlemlenmiştir.

Quadrotor yapısal olarak incelendiğinde, denetimi yapılan yuvarlanma, yunuslama açılarının ve yüksekliğin değişimi quadrotorun rotor itki kuvvetlerinin değişimleri sonucu meydana gelirken, yönelme açisı değişimi rotorlarda oluşan eksenel kuvvetlerin değişimi ile meydana geldiği görülmektedir. Sonuç olarak quadrotorun itki kuvveti değişimlerinden doğrudan etkilenen yuvarlanma, yunuslama açıları ve yükseklik denetimlerinde KKD denetimi daha iyi denetim performansı gösterirken, eksenel kuvvetlerin değişimlerinden etkilenen yönelme açısı denetiminde GAD denetimi daha iyi denetim performansı göstermiştir.

\section{Semboller Listesi;}

$E$ : Yer koordinat ekseni

$B$ : Quadrotor gövde koordinat ekseni

$r$ : İki eksen arasındaki mesafe

$R$ : Dönüşüm matrisi

$\phi$ : Yuvarlanma açısı

$\theta$ : Yunuslama açısı

$\psi:$ : önelme açısı

$J$ : Quadrotorun diyagonal atalet matrisi

$\omega$ : Quadrotorun açısal hız vektörü

$\dot{\omega}$ : Quadrotorun açısal ivme vektörü

$J_{r}:$ Rotor ataleti

$\Omega_{r}$ : Quadrotorun z eksenindeki dönüsel dengesizliği

$F_{i}$ : i'inci rotorun itki kuvveti

$M_{i}$ : i'inci rotorun momenti

$b$ : Aerodinamik kuvvet sabiti

$l \quad$ : Quadrotorun merkezinden rotora olan uzaklık

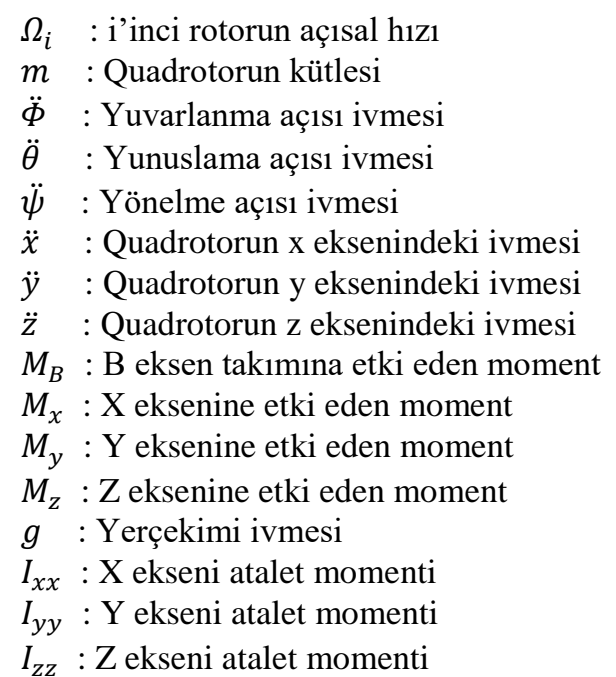

\section{Kaynaklar}

[1] Suiçmez EC, Kutay AT. Dört rotorlu bir insansız hava aracının geri adımlamalı yöntemi ile yol takibi kontrolü, Havac1l1k Ve Uzay Teknolojileri Dergisi. 2014; 7(2): 1-13.

[2] Liang X, Hu Y. Tracking Control and Differential Flatness of Quadrotor with Cable-suspended Load, 2019 IEEE 3rd Information Technology, Networking, Electronic and Automation Control Conference (ITNEC), 15-17 Mart 2019, Chengdu-China. 88-92.

[3] Özçelik AE, Beşdok E. Model helikopter ile yapılan küçük ölçekli fotogrametrik alımların çevre ve arazi gözlemlerinde kullanılabilirliği üzerine bir ön çalışma, TMMOB Coğrafi Bilgi Sistemleri Kongresi, 02-06 Kasım 2009, İzmir. 12-17.

[4] Aksal A, Arıkan KB. Dengelenmemiş dört rotorlu hava taşıtının yönelim dinamiğinin uyarlamalı gürbüz denetimi, Savunma Teknolojileri Kongresi, SAVTEK, Ankara, 2014. 
[5] Selim E, Uyar E, Alcı M. Quadrocopterin matematiksel modeli ve kontrolü. Otomatik Kontrol Ulusal Toplantıs1; 2628 Eylül 2013, Malatya. 548-553.

[6] Romeo F, Héctor R, Alejandro D. Comparative Analysis of Continuous Sliding-Modes Control Strategies for QuadRotor Robust Tracking, Control Engineering Practice, ELSEVIER, 18 June 2019, 241-256.

[7] Xiwei W, Bing X, Yaohong Q. Modeling and Sliding Mode-Base Attitude Tracking Control of a Quadrotor UVA with Time-Varying Mass, ISA Transactions, ELSEVIER, 6 August 2019, 1-8.

[8] Gan Y, David C, Rita C, Carlos S. Nonlinear Backstepping Control of a Quadrotor Slung Load System, ASME Transactions on Mechatronics, IEEE, 2019, 1-11.

[9] Marcos R, Jesus S, Eduardo A. Observer-Based Time-Varying Backstepping Control for a Quadrotor Multi-Agent System, Journal of Intelligent \& Robotic Systems, Springer, 22 May 2018, 135-150.

[10] Liang Y, Yongchun L, Da L, Qiang H. Adaptive Sliding Mode Control for Multi-UAV Systems with Parametric Uncertainties, Materials Science and Engineering 569, IOP Conference, 2019, 1-7.

[11] Xuerui W, Sihao S, Erik K, Qiping C. Quadrotor Fault Tolerant Incremental Sliding Mode Control Driven by Sliding Mode Disturbance Observers, Aerospace Science and Technology, ELSEVIER, 6 March 2019, 417-430.

[12] Ling Z, Liuwei, Yuanqing X, Peng L. Attitude Control of for Quadrotors Subjected to Wind Disturbances Via Active Disturbance Rejection Control and Integral Sliding Mode Control, Mechanical Systems and Signal Processing, ELSEVIER, 17 April 2019, 531-545.

[13] Hadi R, Sima A. Neural Network-Based Adaptive Sliding Mode Control Design for Position and Altitude Control of a Quadrotor UAV, Aerospace Science and Technology, ELSEVIER, 30 April 2019, 12-27.

[14] Fakui W, Weisheng C. Discrete Control of Micro Quadrotor Aircraft via Sampling Feedback, $7^{\text {th }}$ Data Driven and Learning Systems Conference, IEEE, 2019, 914-917.

[15] Xiaobo L, Yao Y, Chang-yin S. A Decoupling Control for Quadrotor UAV Using Dynamic Surface Control and Sliding Mode Disturbance Observer, Spring Nature B. V., 22 June 2019, 781-795.

[16] Ermeydan A, Bir quadrotor'a arıza toleranslı uçuş kontrol sistemi tasarımı. Master, Anadolu Üniversitesi, Ankara, 2015.

[17] Bozkurt E, Dört rotorlu bir insansız hava aracının modellenmesi, tasarımı ve yükseklik denetimi. Master, Fırat Üniversitesi, Elazı̆̆ 2018.

[18] Dikmen İ C, Arısoy A., Temeltaş A. Dikey iniş-kalkış yapabilen dört rotorlu hava aracının (quadrotor) uçuş kontrolü, Havacılık Ve Uzay Teknolojileri Dergisi. 2010; 4(3): 33-40.

[19] Köse E, Abacı K, Aksoy S. Mekanik sistemlerin pid ve kayma kipli kontrol ile modellenmesi ve analizi. National Conference on Electrical, Electronics and Computer Engineering; 2-5 Aral1k 2010; Bursa. 179-183.

[20] ElKholy H, Dynamic modeling and control of a quadrotor using linear and nonlinear approaches. Master, The American University In Cairo, Cairo, 2014.

[21] Sekban H, Can K, Baş̧̧i A. İkili tank sıvı-seviye sisteminin p1 ve geri adımlamalı kontrol yöntemleri ile kontrolü ve performans analizi. ELECO İnternational Conference on Electrical and Electronic Engineers; 01-03 Aralık 2016, Erzurum. 272-277. 